\title{
Labor Informality Bias of a Poverty-Alleviation Program in Argentina
}

\section{Leonardo Gasparini, Francisco Haimovich \& Sergio Olivieri}

To cite this article: Leonardo Gasparini, Francisco Haimovich \& Sergio Olivieri (2009) Labor Informality Bias of a Poverty-Alleviation Program in Argentina, Journal of Applied Economics, 12:2, 181-205, DOI: 10.1016/S1514-0326(09)60012-X

To link to this article: https://doi.org/10.1016/S1514-0326(09)60012-X
8 (c) 2009 Taylor and Francis Group, LLC

\section{曲 Published online: 22 Jan 2019.}

\section{Submit your article to this journal $\sqsubset$}

\section{Џ Article views: 211}

\section{Q View related articles 두}

Citing articles: 3 View citing articles $\square$ 


\title{
LABOR INFORMALITY BIAS OF A POVERTY-ALLEVIATION PROGRAM IN ARGENTINA
}

\author{
Leonardo Gasparini*, Francisco Haimovich \\ ANd Sergio Olivieri \\ Universidad Nacional de La Plata
}

Submitted January 2008; accepted January 2009

In 2002, in the midst of a serious macroeconomic crisis, Argentina implemented a large social program (the Programa Jefes de Hogar, $\mathrm{PJH}$ ) that provides cash transfers to unemployed household heads meeting certain criteria. In practice, the difficulty in monitoring the unemployment requirement for informal (unregistered) workers would imply a disincentive for the program participants to search for a formal job. By applying matching techniques we evaluate the empirical relevance of this prediction during the period of strong economic growth that followed the crisis. We find some evidence on the informality bias of the PJH when the value of the cash transfer was relatively high compared to wages in the formal labor market.

JEL classification codes: D31, I38

Key words: informality, employment, Argentina, evaluation, program, Jefes, poverty

\section{Introduction}

In the midst of one of the most serious economic crisis of its history, Argentina implemented a large poverty-alleviation program, named Programa Jefes de Hogar (henceforth, PJH). This program combines features of a workfare and a conditional cash transfer program. The PJH was aimed at providing cash transfers to those

\footnotetext{
* Leonardo Gasparini (corresponding author): Center for Distributional, Labor and Social Studies (CEDLAS), Universidad Nacional de La Plata, Calle 6 entre 47 y 48, oficina 516, 1900 La Plata, Argentina; e-mail leonardo@depeco.econo.unlp.edu.ar.Francisco Haimovich: fhaimovich@depeco.econo.unlp.edu.ar. Sergio Olivieri: solivieri@depeco.econo.unlp.edu.ar. We are very grateful to María Laura Alzúa, Omar Arias, Mariana Conte Grand, Daniel Kostzer, Juan Manuel Moreno, Jorge Streb, three anonymous referees, and seminar participants at Universidad Nacional de La Plata, LACEA Network of Inequality and Poverty, Asociación Argentina de Economía Política, and International Economic Association for helpful insights, comments and suggestions. The usual disclaimer applies.
} 
unemployed household heads with children at school. The belief that poverty was closely related to unemployment led to include the unemployment requirement as a targeting device.

In theory, conditioning on unemployment implies a full taxation on incomes for the program participants. However, in practice, the monitoring of the program requirements is not perfect, and hence a worker may manage to hold a job and the PJH benefits at the same time. The probability of being in this situation is highly dependent on the visibility of the job. In particular, formal jobs that provide social security benefits are included in administrative records, and hence are difficult to hold along with PJH benefits. Therefore, the unemployment requirement of the PJH would imply a disincentive for beneficiaries to search for a formal registered job.

In practice, however, the informality bias of the program might be negligible. The monitoring of the program may be weak, so participants may not fear losing the transfer by accepting a formal job. It could also be the case that the supply of formal jobs for the typical beneficiary of the PJH is so low that the informality effect of the program becomes insignificant, or that in a segmented market framework wages and labor benefits in the formal sector are so high that all workers would accept an offer from a formal job even when having to resign the program cash transfer.

In this paper, we apply non-experimental matching techniques to assess the impact of the $\mathrm{PJH}$ on labor informality during a period of strong economic growth. Between 2002 and 2005 the Argentine economy grew at an annual 8\% rate, driving employment, and in particular formal employment up. We investigate whether PJH participants were more reluctant to accept formal jobs in this booming economy than their non-participant counterparts. We do find evidence on the informality bias of the PJH but restricted to the period when the gap between the cash transfer and wages in the formal labor market was narrow. The effect of the distortion vanished when wages in formal jobs went substantially up while the value of the PJH transfer remained fixed.

Being the largest cash transfer poverty-alleviation program ever implemented in Argentina, the PJH has drawn the attention of researchers. The first and main contribution is Galasso and Ravallion (2003) who apply propensity score matching techniques to estimate the program's impact on employment and poverty. They find that the PJH increased employment among participants, half coming from a reduction in unemployment and half from a reduction in inactivity. The estimated impact on income poverty was rather small. Almost all the literature has followed the motivation of Galasso and Ravallion (2003) and concentrated on the employment and income 
consequences of the program. ${ }^{1}$ Only a few authors mention its possible informality bias, but no serious attempts are made to estimate it. On the other hand, official studies report a significant number of transitions from the PJH to formal employment during the economic recovery, but they fail to consider a counterfactual. ${ }^{2}$

The rest of the paper is organized as follows. In section II we briefly describe the main characteristics of the Programa Jefes de Hogar, the theoretical predictions about the effects of the program on employment and labor informality, and some preliminary evidence. The methodology is outlined in Section III, while the main results of the paper are shown in Section IV. We end in section V with a discussion of the results and some concluding remarks.

\section{The Programa Jefes de Hogar}

\section{A. Main characteristics}

Argentina fell into a severe economic and social crisis at the end of 2001. The resignation of President de la Rua was followed by the collapse of the Convertibility Plan (pegging the Argentine peso to the dollar), the subsequent devaluation, and the default on the external debt. The economy entered a phase of severe contraction. Unemployment rate rose sharply from 16\% in May 2001 to 21\% in May 2002. The proportion of people living below the official poverty line reached $38.4 \%$ by October 2001 and jumped to $57.5 \%$ one year after. ${ }^{3}$ The Programa Jefes de Hogar was implemented in the first half of 2002, as an emergency response to the economic and social unrest. ${ }^{4}$

The PJH quickly became the largest poverty-alleviation program in Argentina ever. In the second half of 2002 the program had 2 million beneficiaries, representing $10 \%$ of the adult population (aged 18 to 65) in Argentina. The cash transfers of the $\mathrm{PJH}$ reached around $15 \%$ of all households in the country. ${ }^{5}$ In certain regions the

\footnotetext{
${ }^{1}$ See López Zadicoff and Paz (2003, 2004), Miller (2004), Bogani et al. (2005), and Ronconi et al. (2005).

${ }^{2}$ See, for instance, Ministerio de Trabajo (2004).

${ }^{3}$ Own estimates using the official moderate poverty line. See Gasparini (2006).

${ }^{4}$ The program was formally created by the Decreto 565/2002 in April, 2002.

5 The size of the program is also large when compared to international standards. For instance, the famous Progresa covered 9\% of Mexican households in 2002.
} 
share was as high as $40 \%$ (e.g., Formosa and Chaco). The number of beneficiaries has been decreasing since 2003 due to more strict administrative controls, and the recovery of the labor market.

The $\mathrm{PJH}$ is a poverty-alleviation conditional cash transfer (CCT) program. ${ }^{6} \mathrm{The}$ main benefit is a cash transfer of 150 pesos (around US\$50) per month to each eligible individual. The level of the cash transfer was established below the average market wage for full-time unskilled workers to encourage people to seek for a genuine job. According to the program rules, the PJH should provide aid only to unemployed household heads with dependents under 18 who are enrolled in school (or dependents of any age who are disabled). ${ }^{7}$ The program is also available to spouses or partners who are pregnant.

The conditionality of the transfer is based on two characteristics that are difficult to define and monitor: being head of the household, and being unemployed. In particular, verifying unemployment is problematic in an economy where more than half of the employment is in the informal (i.e. unregistered) sector (Gasparini 2006; Gasparini and Tornarolli 2007). All the government can do at a reasonable cost is checking whether a PJH participant has a formal registered job, and denying the benefits if so. In fact, after the program was launched the government started to cross information with the national register of formal jobs (SIJP), the unemployment insurance, and other small social programs. Workers holding a formal job recorded in the SIJP system were eventually deleted from the list of beneficiaries of the PJH (around 3\%). For the most part, the unemployment requirement of the program became a requisite for not having a formal registered job.

The requirement of being the head of the household is also ambiguous and difficult to monitor. In practice it became a restriction to avoid that both the actual head of the household and her/his spouse apply to the program at the same time. More than half of the PJH participants are not household heads, according to what they report to the national household survey (own calculations).

In addition, the PJH requires the individual to carry out counterpart work in order to receive the cash transfer. Participants have to do 20 hours of basic community work, training activities, school attendance or employment in a private company

\footnotetext{
${ }^{6}$ See Galasso and Ravallion (2003), Monza and Giacometti (2003), Golbert (2007) and Moreno (2008) for further discussion on the characteristics of the $\mathrm{PJH}$.

${ }^{7}$ Although the $\mathrm{PJH}$ is a conditional cash transfer program, it was not designed following Mexico's Progresa, as was the case in most Latin American countries. Some features of the PJH, chiefly among them the unemployment requirement, are not shared by the CCTs of other countries.
} 
with a wage subsidy for six months. Some studies and plenty of anecdotal evidence reveal the unclearness of how strictly the work requirements are enforced (see Moreno 2008 and Ministerio de Trabajo 2004).

Although the program was promoted as a social right available to everyone complying with the requirements, the limited funds forced the authorities to apply a rationing mechanism. The Program was officially launched in April 2002, but given the massive demand for benefits, the application process closed on June 2002. The program was assigned on a first-come-first-served basis. People who applied later were rationed out of the program.

\section{B. Labor incentives}

The structure of the PJH implies a potential distortion on the supply for labor. The program is aimed at unemployed individuals. According to the law, a person who works in the labor market is not entitled to the program even when the job is sporadic, or the wage rate is so low that the worker is considered poor. The program requires participants to work a certain number of hours in community works, which turns the PJH into a workfare program.

Figure 1 depicts the consumption (C)-leisure (L) choice of an eligible person who initially faces a wage rate $w_{1}$ equal to the slope of the line $I J$, and is endowed with a non-labor income $I$. The kinked budget constraint is TIJ. The Programa Jefes de Hogar provides a cash transfer to all unemployed persons. Without any requirement to get the subsidy, the budget constraint would now include point $P$. However, participants are supposed to comply with the work requirement. For simplicity, we model that requirement as a reduction in the time available for leisure or for working in the market. If the time needed to comply with the requirement is the distance $B P$, then the new available point is $B$ instead of $P$. The new budget constraint is then the original one before the program (TIJ) plus point $B$.

Notice that the structure of the program in theory implies full disincentives to work. If a program participant located at $B$ decides to work one hour, s(he) would lose the whole transfer and go to a point in the initial budget constraint close to $I$, which would be very likely worse than staying at $B .{ }^{8}$ The individual will abandon the program when the wage goes up to $w_{2}$ (or higher) and the budget constraint shifts to $T I F$. Notice that there is a period when the economy recovers and the real

\footnotetext{
${ }^{8}$ The choice depends on the indifference map: individuals with strong preferences for leisure may prefer a point on the original budget line close to $I$ than point $B$.
} 
Figure 1. Labor incentives of the Programa Jefes de Hogar

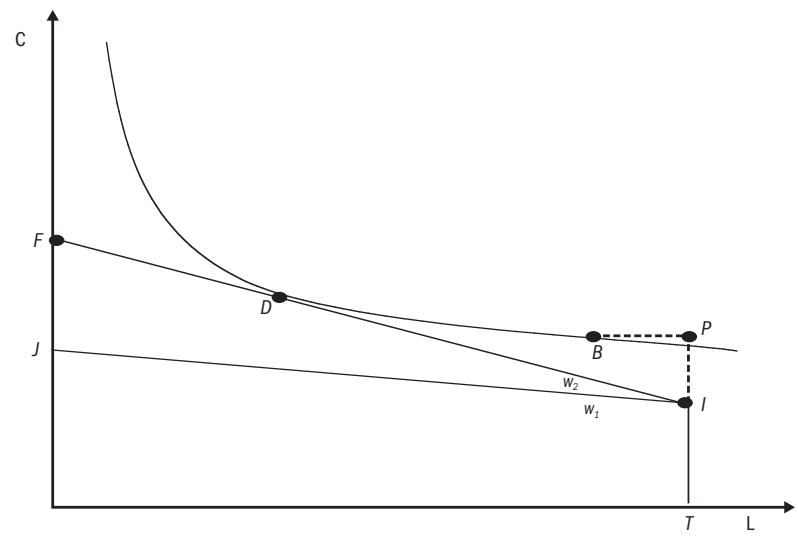

wage grows from $w_{1}$ to $w_{2}$, in which there are jobs in the market, wages are increasing, but program participants prefer to stay in the program. Anecdotal evidence points to the fact that many participants do not comply with the work requirement. In that case the program adds point $P$ (not $B$ ) to the budget constraint, and the negative effects on the labor supply are even larger.

As commented above, although in theory the program is intended only for the unemployed, administrative weakness precludes the government to check the unemployment condition for people who carry out informal activities or hold informal salaried jobs. In addition, as the program was mainly intended to alleviate poverty, not unemployment, many local officials in charge of administering the program find it difficult to deny the transfer to a poor family, even when knowing that the head has some labor activity. For these reasons, in practice the unemployment requirement is replaced by an implicit structure in which the probability of losing the program is much higher for workers in the formal registered sector, than for the unemployed/inactive and those working in the hidden economy.

Suppose a situation of economic crisis with high unemployment. The individual depicted in Figure 2 faces a zero wage rate and then s(he) is initially at point $I$. Assuming no work requirement, the program allows that individual to go to point P. Trivially, there is no distortion in this case, due to the lack of labor market opportunities. Assume now that the economy recovers, and that in a segmented market framework, the individual has the opportunity to work in a formal job at hourly wage $w_{F}$ or in an informal activity at hourly wage $w_{I}$. In principle the formal job is better, but it has a caveat: while the participant can keep the PJH while working 
in the informal sector, $\mathrm{s}(\mathrm{he})$ has to quit the program if chooses the formal job. The budget constraint in the former case is TPM, while it becomes TIF in the latter. Many individuals will find optimal to choose a point in the segment $D P$, i.e. stay in the program and work in the informal sector, even when having an offer for a formal job at a higher wage rate. ${ }^{9}$ Of course, as formal wages grow relative to the value of the transfer and the informal wage, the individual will eventually quit the program.

Although the worker may prefer to refuse an offer for a formal job if the wage rate is not sufficiently high, local authorities may push him (her) to accept it, if by doing that, they could have an additional slot available for a new PJH beneficiary. In practice, however, federal authorities did not easily allow new participants into the program. The national government sought to reduce the coverage of the PJH, as the labor market recovered and original participants left the program. In that scenario, and given that the program was funded at the federal level, local governments had low incentives in promoting people to find formal jobs and quit the program.

There are some reasons why the disincentive to formal jobs may not operate in the real world. A trivial one is low enforcement capacity: authorities might not want or be able to punish beneficiaries working in the formal sector.

Figure 2. Informal work incentives of the Programa Jefes de Hogar

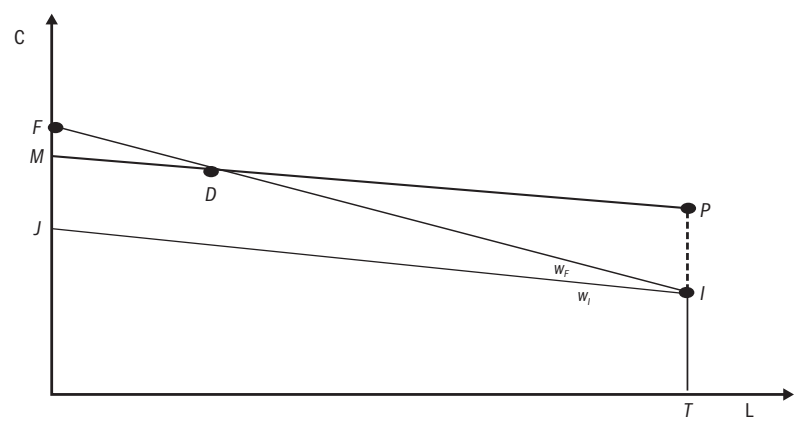

\footnotetext{
${ }^{9}$ The bias toward labor informality may extend to other members of the household. The PJH is mostly held by women. If the female participant's husband is offered a formal registered job, he should take into account the increase in the probability of losing the PJH benefits, and might prefer to reject the offer.
} 
A second possibility arises in a segmented labor market where the wage distance (including social benefits) between a formal and an informal job is larger than the cash transfer of the program. In that case, there might be no individuals in the "margin". Faced to the opportunity of a formal job, a PJH participant would have no doubt in accepting it, even when that implies quitting the program. In that case, trivially, the program does not imply any additional distortion on the workers' choice.

A third possibility is that the program participants have certain characteristics that make them less demanded in the formal labor market. Most program participants are unskilled young women: even when the economy starts to grow and the economic perspectives are good, firms may be reluctant to offer a formal contract to these new workers. If that is the case, the program might have a theoretical bias toward labor informality, but in practice it could be quantitatively negligible.

A fourth related case pictures program participants as people with preferences biased against formal employment, given the commitments required by these jobs (hours of work, place of work, schedules). For instance, some women in charge of raising children may participate in the $\mathrm{PJH}$, since they may find easy to negotiate a more flexible work requirement, or to avoid it altogether, and they may refuse a formal job with more strict work conditions. Hence, in these cases the informality bias may be quantitatively very small.

In summary, as the economy recovers program participants may be more reluctant to accept formal jobs than non-participants with the same characteristics. The PJH implies in theory an informality bias that, however, for many reasons may not be quantitatively relevant in practice. The rest of the paper is aimed at providing evidence on that issue.

\section{Data and preliminary evidence}

The national household survey in Argentina (Encuesta Permanente de Hogares, EPH) has information on labor variables, and identifies the beneficiaries of the Programa Jefes de Hogar. The EPH is carried out by the Instituto Nacional de Estadística y Censos (INDEC) since the early 1970s in the Greater Buenos Aires area, and since the 1980s in most large cities (more than 100,000 inhabitants). During 2003 a major methodological change was implemented by INDEC, including changes in the questionnaires and in the timing of the survey visits. The new survey (know as EPH Continua, or EPHC) is now conducted over the whole year. The modifications of the questionnaire in the labor section were particularly important, 
and led to substantial discontinuities in the series of all employment variables. For instance, Gasparini (2006) reports that the share of salaried workers in informal jobs (defined as absence of social security rights) is 0.388 when using the May 2003 $\mathrm{EPH}$, and 0.437 when using the EPHC for the second half of 2003. ${ }^{10}$

The PJH started in 2002 and questions on that program showed up in the EPH of that year. Given the changes in the survey commented above we decided to work only with the EPHC starting in the second half of 2003. In addition, 2003 is also the year when the economic recovery began in Argentina after four years of stagnation and recession. The EPHC covers 28 large urban areas which are home to around $70 \%$ of the Argentine urban population. Since the share of urban areas in Argentina is $87 \%$, the sample of the EPHC represents around $60 \%$ of the total population of the country. ${ }^{11}$

The EPHC is a rotating panel: individuals are interviewed in two consecutive rounds (quarters), left out for two rounds, and surveyed again in the next two quarters. These short panels are used to assess changes in the labor status of individuals. We work with the datasets containing information for each half (not quarter) of the year. ${ }^{12}$ In particular, in Section VI we report results drawn from two panels: 2003II \& 2004-II, and 2004-II \& 2005-II.

As discussed above, the PJH is a large program. In 2003, $11.6 \%$ of the households surveyed by the EPHC reported being beneficiaries of the program (Table 1). That share has been descending over time as the labor market recovered. The relevance of the program in the lowest quintiles of the income distribution is high, although the PJH is far from being universal. In the second half of $2005,30 \%$ of the households in the poorest quintile received transfers from the PJH. That share falls to $17 \%$ in the second quintile and to $6 \%$ in the third. The program is almost inexistent in households of the top quintile, or households where the head has high (tertiary) education. The Programa Jefes has been reasonably targeted to the poor population. Around $80 \%$ of the participants belong to the two bottom income quintiles of the population. The degree of targeting in the poorest $20 \%$ of the population has been increasing over time.

\footnotetext{
10 The EPHC of the first half of 2003 is not available.

${ }^{11}$ It is believed that informality is widespread in rural areas, so the informality bias of the PJH is more likely to appear in urban areas.

${ }^{12}$ Some individuals are interviewed twice in each semester. To avoid overweighting of these individuals, we ignore the second observation in our panels.
} 
Table 1. Share of households with PJH coverage

\begin{tabular}{lcccc}
\hline \multicolumn{4}{l}{ A. By income quintiles } \\
\hline Period & 1 & 2 & 3 & 4 \\
\hline $2003-I I$ & 31.6 & 23.1 & 9.9 & 4.4 \\
$2004-I$ & 32.4 & 22.4 & 9.9 & 3.2 \\
$2004-I I$ & 33.6 & 20.9 & 8.4 & 3.2 \\
$2005-I$ & 33.5 & 19.2 & 7.8 & 2.4 \\
$2005-I I$ & 30.3 & 16.6 & 5.8 & 2.5 \\
\hline B. By education of the household head & & \\
\hline Period & Low & Medium & High & Mean \\
\hline $2003-I I$ & 17.1 & 8.9 & 2.2 & 10.9 \\
$2004-I$ & 16.4 & 9.6 & 1.8 & 10.8 \\
$2004-I I$ & 16.3 & 7.9 & 1.4 & 10.3 \\
$2005-I$ & 15.5 & 7.0 & 1.4 & 9.6 \\
$2005-$ II & 14.4 & 7.1 & 1.0 & 9.0 \\
\hline
\end{tabular}

Notes: Low: primary incomplete. Medium: secondary complete. High: tertiary or college complete. Source: own calculations based on the EPHC.

This paper is aimed at exploring the potential effect of the program on labor informality. There are at least two different concepts that are referred by the term labor informality (see Perry et al. 2007 for a discussion). The "productive" definition pictures informal workers as those in low-productivity, unskilled, marginal jobs, while the "legalistic" or "social protection" definition stresses the lack of labor protection and social security benefits. The productive definition is concerned with the type of job (e.g. salaried vs. self-employed, large vs. small firms), while the social-protection/legalistic definition is concern with the compliance of the labor relationship with some rules, mainly labor protection.

We deal here with the latter definition of informality. Given the information available in the EPHC we define a formal job as one in which the employee reports having the right to a pension ("jubilación") when retired. Unfortunately, the relevant question is only asked to salaried workers. Given that the tax and social security system in Argentina are poorly-developed for the self-employed, in particular for the typical beneficiary of the $\mathrm{PJH}$, we assume that all self-employed workers are informal. We exclude the group of entrepreneurs ("patrones") from the analysis. Also, in order to focus the study on the program target population, we restrict the sample to people aged 18 to 60 , in deciles 1 to 6 , and without tertiary education. 
Table 2 stresses the fact that the number of program participants has been falling since 2003 as the labor market recovered. The share of PJH participants in the sample fell from $12.9 \%$ in 2003 to $10.1 \%$ in 2005. Participants complying with the labor requirement are officially counted as employed. The share of "employed" $\mathrm{PJH}$ participants in total employment in the sample fell from $19.9 \%$ to $13 \%$ in two years.

Table 2. Share of PJH participants in population and employment, and labor status

\begin{tabular}{|c|c|c|c|c|c|}
\hline & $2003-11$ & $2004-1$ & $2004-I I$ & $2005-1$ & $2005-1$ \\
\hline \multicolumn{6}{|c|}{ Shares of PJH participants in population and employment } \\
\hline \multicolumn{6}{|l|}{ All } \\
\hline -Share in population & 12.9 & 12.6 & 11.4 & 11.5 & 10.1 \\
\hline -Share in employment & 19.9 & 18.9 & 16.6 & 15.7 & 13.0 \\
\hline \multicolumn{6}{|l|}{ Males } \\
\hline -Share in population & 8.8 & 7.6 & 6.8 & 6.4 & 5.0 \\
\hline -Share in employment & 11.3 & 9.5 & 8.2 & 7.7 & 5.6 \\
\hline \multicolumn{6}{|l|}{ Females } \\
\hline -Share in population & 16.7 & 17.0 & 15.7 & 16.1 & 14.8 \\
\hline -Share in employment & 33.7 & 33.4 & 30.3 & 29.1 & 25.7 \\
\hline \multicolumn{6}{|l|}{ Labor status } \\
\hline \multicolumn{6}{|l|}{ All population in sample } \\
\hline -Employed - formal & 12.9 & 13.4 & 14.2 & 14.2 & 15.5 \\
\hline -Employed - informal & 44.6 & 44.8 & 45.2 & 44.4 & 44.4 \\
\hline -Unemployed & 15.1 & 14.6 & 12.9 & 11.9 & 10.7 \\
\hline -Inactive & 27.4 & 27.1 & 27.6 & 29.5 & 29.4 \\
\hline \multicolumn{6}{|l|}{ Non-participants } \\
\hline -Employed - formal & 14.7 & 15.3 & 16.0 & 16.0 & 17.2 \\
\hline -Employed - informal & 38.0 & 38.7 & 39.9 & 39.8 & 40.7 \\
\hline -Unemployed & 17.1 & 16.4 & 14.2 & 13.1 & 11.5 \\
\hline -Inactive & 30.2 & 29.6 & 29.9 & 31.2 & 30.7 \\
\hline \multicolumn{6}{|l|}{ Participants } \\
\hline -Employed - formal & 0.5 & 0.5 & 0.6 & 0.4 & 0.6 \\
\hline -Employed - informal & 88.8 & 87.5 & 86.7 & 80.1 & 77.2 \\
\hline -Unemployed & 2.1 & 2.1 & 3.0 & 3.4 & 4.2 \\
\hline -Inactive & 8.5 & 9.9 & 9.7 & 16.1 & 18.0 \\
\hline
\end{tabular}

Notes: sample composed of adults aged 18 to 60 , deciles 1 to 6 , without tertiary education. Source: own calculations based on the EPHC. 
In the period 2003-2005, as the economy recovered from a long recession, the unemployment rate fell substantially, fueled by a sizeable increase in formal employment, and an increase in inactivity (Table 2). While in $200312.9 \%$ of people in the sample had a formal job, that share grew to $14.2 \%$ in 2004 , and $15.5 \%$ in 2005. The share of people in informal jobs remained roughly unchanged. In order to keep the PJH, the worker in principle should not accept a formal job. Table 2 shows that the great majority of $\mathrm{PJH}$ participants are informal workers. ${ }^{13}$

As discussed above, while the law establishes a set of conditions to apply to the $\mathrm{PJH}$, in practice some of them are not enforced by the authorities. It is interesting to notice that while only $3 \%$ of people who legally qualify to the program (unemployed household heads with children at school) are actual beneficiaries, participation is much higher (26\%) for those household heads with children at school who are not unemployed, but who do not hold a formal job.

As mentioned above, the incentives to look for a formal job substantially varied across the period under analysis. The cash transfer of the program was fixed in nominal terms (\$150), while the labor market recovered and wages in the formal sector substantially increased. While the PJH transfer represented $75 \%$ of the minimum wage in the formal sector in 2003, that share fell to just $24 \%$ in $2005 .{ }^{14}$

Table 3 shows earnings in the formal sector, and labor income in part-time informal jobs. ${ }^{15}$ The column labeled Diff 1 reports the difference between earnings in a formal job and the PJH transfer, i.e. the gap relevant for the decision of a PJH participant not working in the market, or expecting to keep his current informal activities if hired in a formal job. That difference doubled between 2003 and 2005. If by working in the formal sector the worker had to abandon his activities in the informal sector, the difference reported in the last column would be more relevant. In this case the earnings gap more than doubled. The results suggest that the monetary incentives to look for a formal job greatly increased between 2003 and 2005. Many workers for whom leaving the PJH to get a formal job was not optimal in 2003 probably modified that decision in 2005 . The distortion introduced by the unemployment requirement of the $\mathrm{PJH}$ might have been losing relevance over time.

\footnotetext{
${ }^{13}$ Notice that showing that formal employment grew for non-participants but not for participants is not a sign of the informality bias of the program, since participants may be abandoning the program to become formal workers.

${ }^{14}$ The minimum wage was fixed at $\$ 200$ from 1994 to the end of 2004 when it jumped to $\$ 450$. In 2005 it scaled up to $\$ 630$.

${ }^{15}$ The table displays wages at percentile 25 , but results are robust to this choice.
} 
Table 3. Earnings and PJH transfers

\begin{tabular}{lccccc}
\hline Period & $\begin{array}{c}\text { PJH transfer } \\
\text { (i) }\end{array}$ & $\begin{array}{c}\text { Formal wage } \\
\text { (ii) }\end{array}$ & $\begin{array}{c}\text { Informal wage } \\
\text { (iii) }\end{array}$ & $\begin{array}{c}\text { Diff } 1 \\
\text { (ii)-(i) }\end{array}$ & $\begin{array}{c}\text { Diff } 2 \\
\text { (ii)-(i)-(iii) }\end{array}$ \\
\hline All & & & & & \\
$2003-$ II & 150 & 366 & 120 & 216 & 96 \\
$2004-I$ & 150 & 397 & 149 & 247 & 98 \\
$2004-$ II & 150 & 445 & 149 & 295 & 145 \\
$2005-$ I & 150 & 502 & 155 & 352 & 198 \\
$2005-$ II & 150 & 565 & 180 & 415 & 235 \\
Males & & & & & \\
$2003-$ II & 150 & 398 & 150 & 248 & 98 \\
$2004-I$ & 150 & 417 & 197 & 267 & 69 \\
$2004-$ II & 150 & 485 & 199 & 335 & 135 \\
$2005-I$ & 150 & 515 & 206 & 365 & 159 \\
$2005-$ II & 150 & 595 & 242 & 445 & 203 \\
Females & & & & & \\
$2003-$ II & 150 & 295 & 99 & 145 & 46 \\
$2004-I$ & 150 & 305 & 100 & 155 & 55 \\
$2004-$ II & 150 & 352 & 101 & 202 & 102 \\
$2005-I$ & 150 & 402 & 121 & 252 & 131 \\
$2005-$ II & 150 & 406 & 121 & 256 & 135 \\
\hline
\end{tabular}

Notes: adults in deciles 1 to 6 without tertiary education; values at percentile 25. Source: own calculations based on the EPHC.

\section{The methodology}

We apply non-experimental methods of impact evaluation to assess the labor informality bias of the PJH (see Ravallion 2005 for a review of those methods). The population is divided into two groups: those who receive the program (treated, $D_{i}=1$ ) and those who do not (non-treated, $D_{i}=0$ ). Let $Y_{i}^{k}$ be the outcome to evaluate for individual $i$ in situation $k$ regarding treatment. In our paper $Y$ is a binary variable equal to one if the worker has a formal job. Ideally, we would like to estimate the whole distribution of $G_{i}=Y_{i}^{T}-Y_{i}^{C}$, where $Y_{i}^{T}$ is the outcome if the individual participates in the program and $Y_{i}^{C}$ is the outcome if (s)he does not participate. The problem of impact evaluation is that one of the two terms in $G_{i}$ is unobservable. We just observe outcome $Y_{i}\left(Y_{i}=Y_{i}^{T}\right.$ if $D_{i}=1$ and $Y_{i}=Y_{i}^{C}$ if $\left.D_{i}=0\right)$. In particular, in our case we observe the formal/informal decision of the PJH participants, but we do not know what that decision would have been if they had not received the program, i.e., the counterfactual outcomes for the participants. 
Given that estimating the whole distribution of $G_{i}$ is very difficult, in most cases the analysis is restricted to estimate specific parameters. In particular, the majority of the impact evaluation literature is aimed at estimating the average treatment effect on the treated conditional on other covariates $X$ :

$\operatorname{ATET}\left(X_{i}\right)=E\left(Y_{i}^{T}-Y_{i}^{C} \mid X_{i}, D_{i}=1\right)$.

A simple estimator of ATET is just the mean difference in outcomes between participants and the non-treated group. The general condition for zero bias is mean independence, also known as "ignorability" (see Lee 2005):

$E\left(Y_{k} \mid D\right)=E\left(Y^{k}\right), \quad k=T, C$.

The best way to assure ignorability is to design a social experiment in which individuals are randomly assigned into the treatment and control group, so that both groups become statistically equivalent. The PJH was not designed as a social experiment. Participants were chosen according to certain rules, and in principle those meeting the requirements were entitled to the program. However, given the massive demand for social assistance in times of a harsh recession and the scarce fiscal resources available, the government decided to close the admission soon after it had been opened, and then most potential beneficiaries were left out of the program.

In this framework, and given the available information, our research strategy is simple. In a scenario of strong increase in the availability of formal jobs, we compare the proportion of PJH participants who find a formal job between $t_{1}$ and $t_{2}$ with that proportion for a group of non-participants with similar observable characteristics. To improve the matching we restrict the analysis to individuals who are not holding a formal job at time $t_{1}$ : almost all $\mathrm{PJH}$ participants are in that situation. In that sense, although we are using longitudinal data, the first stage of the implicit diff-in-diff procedure is trivial, as the outcome variable (the share of formal workers) is zero for both treatment and comparison groups.

The key assumption in this strategy is that in the absence of the program the PJH participants will be moving to the formal sector at the same rate as a matched group of non-participants. Of course, the assumption may be restrictive, as the factors affecting treatment may also affect the changes in the outcome (labor formality). See below for a discussion of this crucial point.

Formally, we estimate

$$
A T E T=\frac{1}{n_{T}} \sum_{i \in t}\left(Y_{i 2}^{T}-\sum_{j \in C_{i}} W_{i j} Y_{j 2}^{C}\right),
$$


where $n_{T}$ is the size of the panel, $T$ the set of treatment observations, $C_{i}$ the set of control observations and $W_{i j}$ the weight of observation $j$ in the group of matches for participant $i . Y_{i 2}^{T}$ is a binary variable equal to 1 if individual $i$, who participated in the program in the first year of the panel, finds a formal job in the second year. Similarly, $Y_{j 2}^{C}$ is a binary variable equal to 1 if individual $j$, who did not participate in the program in the first year of the panel (and was not a formal worker), finds a formal job in the second year.

The matching is carried out based on the propensity score, i.e., the probability of receiving treatment conditional on pre-treatment characteristics $P\left(Z_{i}\right)$. Rosenbaum and Rubin (1983) show that if the participation decisions are independent across individuals, and if outcomes $Y$ are independent from actual participation given $Z_{i}$, then outcomes are independent from participation given $P\left(Z_{i}\right)$. This theorem allows carrying out the matching on scalars $P\left(Z_{i}\right)$ rather than in the multidimensional space of variables $Z$.

To improve the results we perform the matching over the propensity scores conditional on gender and income decile before the transfer, i.e., matched observations should be similar in terms of the propensity score, and identical in terms of gender and income group.

Exact matching on the $P\left(Z_{i}\right)$ is difficult as this is a continuous variable. The literature has proposed several schemes to weight observations with similar propensity scores. In this paper we use radius (of 0.01) matching as the main weighting scheme, as it uses only good quality matches, and does not consider those treatment units who are very different from the comparisons units. We also use kernel and nearest neighbor methods to assess the robustness of the estimates. We apply the technique proposed in Abadie and Imbens (2006a) (nnmatch) that allows for bias correction and delivers the corrected standard errors that usual matching techniques, even with boostrapping, fail to do (Abadie and Imbens 2006b).

Summing up, the outcome $Y$ of each participant $i$ is compared to the weighted mean of a set of non-participants belonging to the same gender and income group, and whose propensity scores are "close" to that of participant $i$. To further improve the matching we restrict the analysis to adults aged 18 to 60 without a tertiary education, belonging to the bottom six deciles of the household income distribution, in the labor force, and without a formal job in the first year of the panel. ${ }^{16}$

\footnotetext{
${ }^{16}$ Galasso and Ravallion (2003) compare the group of PJH beneficiaries with those that have applied to the program but have not received it yet. This pipeline comparison allows them to construct a better counterfactual as applicants may be more similar to actual beneficiaries than non-applicants. Unfortunately, the EPH included the question on application to the PJH only during 2002, so we were not able to use that variable in our study.
} 


\section{Results}

In Table 4 we show the results of estimating a model of participation in the PJH for the sample mentioned above. The probit is estimated in the initial year using only the observations that belong to the panel. The results are similar to those in Galasso and Ravallion (2003), who estimate a somewhat similar model for the crisis period 2001-2002. Women are more likely to be participants. The probability of participation is decreasing in the individual's education (incomplete primary is the omitted category). Even when controlling for family size, the number of children under 18 affects participation. There are significant differences in participation across cities, even when controlling for other observable characteristics.

We show in an Appendix (Figure A1) the histograms for the distribution of the propensity scores for the treated and untreated observations in the survey. While the distributions look very different for the full sample (first row), they became similar as we consider only the matched sample (second row for radio matching procedure, and third row for the nearest neighbor). Table A1 in the Appendix shows the differences in the mean values of a set of covariates between the treatment and the comparison (matched) group. Both groups are similar in terms of observable characteristics. None of the differences between groups are statistically significant in any of the two datasets considered.

The results of the propensity score matching analysis over the panels 2003-2004 (second half of both years) and 2004-2005 (second half of both years) using the radius method are reported in Table 5. Each column shows the share of formal workers in the second year of each panel for two groups: those who were PJH participants in the first year and those in the comparison group. As argued above, the vast majority of participants are informal. We build the comparison group by restricting the choice to informal workers. Therefore, the outcome variable in year 1 is zero by definition in both treatment and comparison groups. The table shows the share of formal workers in the second year of the panel, when some former PJH participants and some former informal workers in the comparison group find a formal job. We report results for the whole sample for each panel, and then separately for men, females, those individuals whose incomes are between the moderate and the extreme official poverty line (the "moderate poor"), and those that are below the extreme line (the "extreme poor"). In each column we report the mean value for the treated and the comparison groups, the difference, the standard error, the corresponding t-value, and the number of treated observations. 


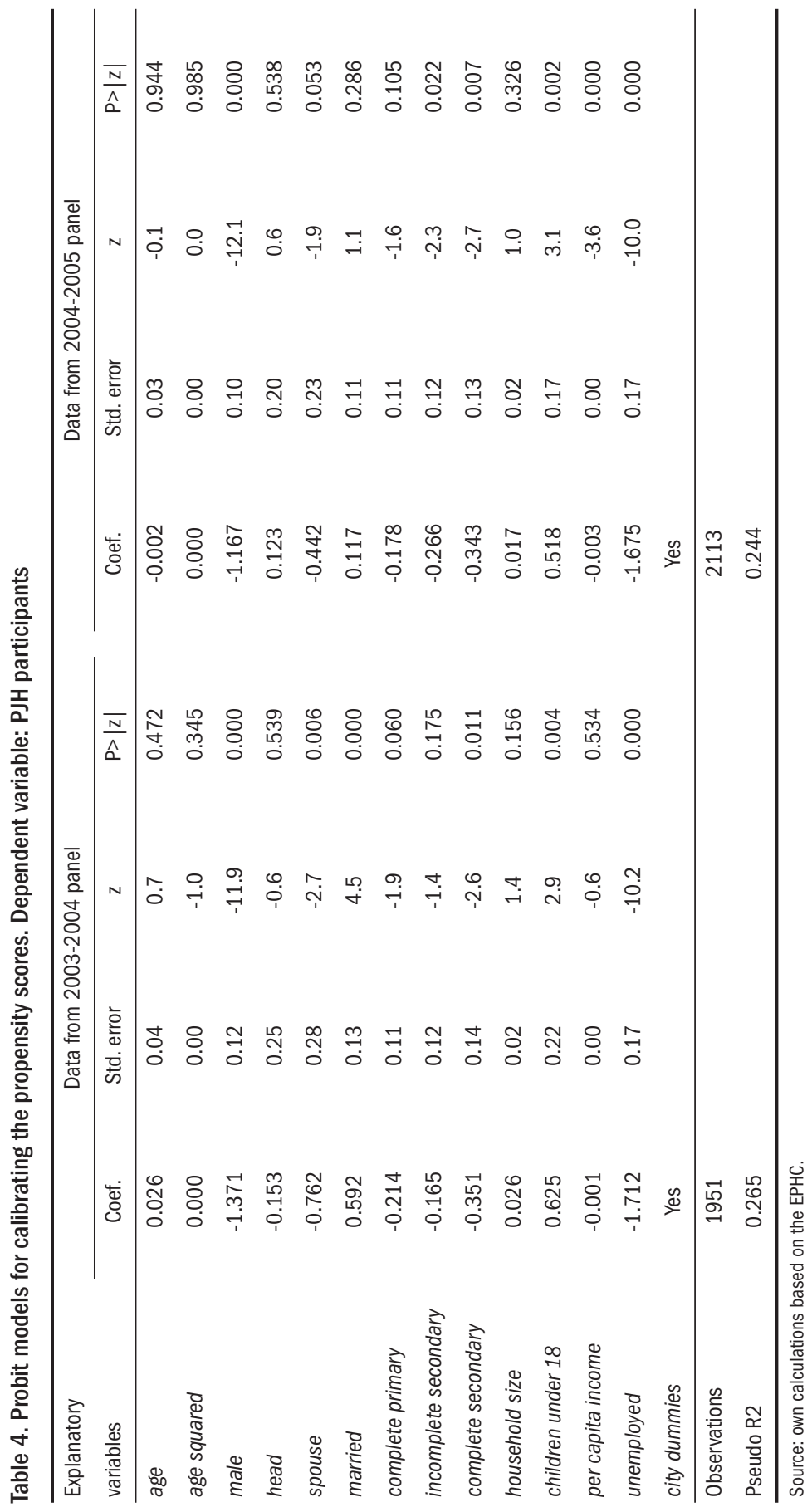


Table 5. Share of individuals with a formal job in year 2

\begin{tabular}{lccccc}
\hline 2003-II/2004-II & All & Males & Females & Moderate poor & Extreme poor \\
\hline Treated & 0.012 & 0.011 & 0.013 & 0.021 & 0.004 \\
Comparison & 0.046 & 0.061 & 0.039 & 0.056 & 0.038 \\
Difference & -0.034 & -0.050 & -0.026 & -0.035 & -0.034 \\
Std. error & 0.012 & 0.015 & 0.012 & 0.022 & 0.014 \\
$\mathrm{t}$ & -2.888 & -3.351 & -2.114 & -1.632 & -2.377 \\
Observations & 562 & 184 & 378 & 241 & 242 \\
\hline 2004-II/2005-II & All & Males & Females & Moderate poor & Extreme poor \\
\hline Treated & 0.039 & 0.091 & 0.019 & 0.037 & 0.041 \\
Comparison & 0.057 & 0.095 & 0.041 & 0.048 & 0.057 \\
Difference & -0.017 & -0.004 & -0.022 & -0.011 & -0.016 \\
Std. error & 0.014 & 0.026 & 0.013 & 0.022 & 0.024 \\
$\mathrm{t}$ & -1.207 & -0.148 & -1.660 & -0.495 & -0.670 \\
Observations & 585 & 164 & 421 & 244 & 220 \\
\hline
\end{tabular}

Notes: average treatment effect on the treated using propensity score matching, radius method, panels 2003-2004 and 20042005 , group of adults aged 18 to 60 in the labor force from deciles 1 to 6 without a formal job in year 1 . Source: own calculations based on the EPHC.

According to the first panel in Table 5, 1.2\% of all PJH participants in 2003 found a formal job one year later. The corresponding share for the comparison group was greater: $4.6 \%$. The difference is statistically significant and economically large. The gap in the jump into formality is substantially larger for males than for females, and approximately the same for the extreme poor and the rest. Similar results arise when using the kernel and the nearest neighbor methods. ${ }^{17}$

Results are qualitative similar in the panel 2004-2005 but quantitatively much weaker. While $3.9 \%$ of $\mathrm{PJH}$ participants moved from the program to a formal job, the corresponding figure for the comparison group was larger $(5.7 \%)$ but not statistically different at 5\%. In fact, the gap between participants and the comparison group vanishes in the case of males.

We interpret these results as evidence of the informality bias of the PJH in the early stage of the program, when the transfer was significant compared to wages in the formal sector. As the nominal value of the transfer remained fixed while the formal labor market strongly recovered, the gap shrunk, and hence the distortion became less important, and possibly negligible.

\footnotetext{
${ }^{17}$ Results are available from the authors upon request.
} 
A multivariate regression framework can provide results on the same issue based on a parametric model. Table 6 reports the results of a probit model for a dummy variable equals to 1 if the individual holds a formal job in year 2 of the panel. The model is run for the same sample discussed above. As right-hand-side variables we include program participation and a set of typical controls. The results in Table 6 are similar than when applying propensity score matching. In the early panel 2003 2004 all marginal effects are negative, and most of them statistically significant. In particular, the impact of the program on the informality decision of males seems large. In contrast, most effects vanish in the panel 2004-2005 when the relative value of the program subsidy collapses.

Table 6. Model of the share of individuals with a formal job in year 2

\begin{tabular}{lccccc}
\hline 2003-II/2004-II & All & Males & Females & Moderate poor & Extreme poor \\
\hline Marginal effect & -0.03 & -0.05 & -0.02 & -0.03 & -0.04 \\
Coefficient & -0.49 & -0.90 & -0.34 & -0.44 & -0.91 \\
Std. error & 0.01 & 0.01 & 0.01 & 0.01 & 0.01 \\
z & -3.30 & -3.86 & -1.46 & -1.83 & -3.19 \\
Observations & 2841 & 1511 & 944 & 1197 & 657 \\
\hline 2004-II/2005-II & All & Males & Females & Moderate poor & Extreme poor \\
\hline Marginal effect & -0.01 & 0.02 & -0.02 & -0.01 & -0.01 \\
Coefficient & -0.10 & 0.10 & -0.34 & -0.14 & -0.17 \\
Std. error & 0.01 & 0.02 & 0.01 & 0.02 & 0.02 \\
z & -0.87 & 0.75 & -1.77 & -0.64 & -0.72 \\
Observations & 3226 & 1663 & 1256 & 1348 & 772 \\
\hline
\end{tabular}

Notes: marginal effect of the PJH participation, panels 2003-2004 and 2004-2005, group of adults aged 18 to 60 in the labor force from deciles 1 to 6 without a formal job in year 1. Control variables: age, age squared, gender, household head, marital status, education, type of household, number of children, per capita income (pre-transfers), employment status, city dummies. Source: own calculations based on the EPHC.

\section{Discussion and conclusions}

We have shown evidence suggesting that program participants moved into formal jobs at lower rates than non-participants with similar observable characteristics, at least in the early stage of the program when the gap between the transfer and earnings in the formal sector was not large. If the assignment into the program had been random, the results could be interpreted as the causal effect of the program on labor informality. However, as discussed above, the program was offered to everyone meeting certain conditions and then rationed by queues, given the limited funds. 
One plausible reason why certain people got the program, while some others with similar observable characteristics did not, is having political and social contacts (sometimes also known as social capital) that facilitated the access to the information about the program and eased the application process (Giovagnoli 2006; Ronconi et al. 2005, Moreno 2008). Social organizations and NGOs had a key role in helping people to successfully apply to the program. On the other hand, the economic literature has stressed the positive impact of social capital on the access to the labor market (see Toledo 2007 for a recent empirical study for Argentina on this issue). For instance, better political contacts could increase the probability of finding a formal job in the local public sector. If having more political and social contacts affects participation in the program and increases employability in the formal sector, then our results on the informality effect of the program will be downwardly biased. The results in Table 6 would suggest that despite being in a better position to enter the formal labor market due to more social capital, PJH participants were more reluctant to accept formal offers, presumably because of the distortion introduced by the program. ${ }^{18}$

Another possibility is that participants, on average, had low preferences for a formal job, or had unobservable characteristics that make them less attractive for formal firms. If that were the case we should find that following the recovery of the labor market a relative low proportion of participants are hired in formal jobs, even in the absence of any distortion coming from the structure of the program. Notice, however, that in this case it is likely that there always exists a gap between participants and non-participants in their formal-job take-up rates. The evidence is not inconsistent with this fact in the case of women: in both panels while around $1.5 \%$ of female participants found a formal job, the corresponding figure for nonparticipants (matched) women is $4 \%$. The hypothesis of PJH participants with low preferences or productivity in formal jobs (relative to their non-participant matched counterparts) is less consistent with the evidence in the case of males. Table 6 shows that when formal wages substantially increased, the rates of entry into the formal sector were similar for male participants and non-participants.

A related alternative states that $\mathrm{PJH}$ participants are less likely to receive or less prone to accept any job offer (formal or informal), and hence the rate of entry into the formal labor market should be lower than for their non-participant counterparts. However, that does not seem the case: the employment rate of program participants

\footnotetext{
${ }^{18}$ If social capital were negatively correlated to employability (e.g., NGOs making an effort to act on the most disadvantaged) the argument could be reversed.
} 
(excluding work in the program) grew faster than the rate for non-participants. A diff-in-diff estimation indicates that PJH beneficiaries in fact did better in terms of finding a genuine employment than their matched untreated counterparts. ${ }^{19}$

Another possibility is that at the time of the program launching some people who qualified for the program had better perspectives of finding a formal job, and then they did not apply for the program. However, that fact may not affect our results since we start the analysis (due to data reasons) one year after the plan was implemented. Our comparison group is formed by people without a formal job in 2003. These workers would have found optimal to apply for the program since the cost of doing that was low, and their perspectives of finding a formal job were surely low in May 2002, given that one year later they are still in the informal sector.

The geographical distribution of the program was not uniform. Some cities captured a disproportionate share of benefits, even when controlling for observable characteristics. Giovagnoli (2006) argues that areas with local authorities "closer" to the federal government were allowed to include proportionally more participants. Cities with a high share of PJH participants may be places where people were less prone to self-select out of the program. In particular, workers with unobservable characteristics that make them more productive, and hence with higher probability of quickly finding a job may have been more likely to apply and obtain the program in cities where the access to the $\mathrm{PJH}$ was easier. If that had been the case, when the economy recovered the jump from the program to formal employment should have been stronger in cities favored by the allocation of the PJH benefits. To provide some evidence on this issue we include in a parametric model similar to that of Table 6 an interaction variable between the individual participation in the program and the local share of PJH participants. In an alternative model we take into account that the allocation of the PJH across geographical areas was likely determined by observable characteristics of the area, like the poverty and the unemployment rate. We then construct a second interaction variable between the individual participation in the program and the residuals of a model of PJH allocation at the city level. The main result in both models is that the interaction effect is positive and significant for females, but not for males. Female participants seem to have been more likely to find a formal job in cities with high coverage of the program..$^{20}$

\footnotetext{
${ }^{19}$ The results of this exercise are included in a longer version of this paper, available upon request.

${ }^{20}$ Again, results are available upon request.
} 
To summarize, although the Programa Jefes de Hogar is legally intended to the unemployed, in practice only those participants that accept a formal job face serious risks of losing the benefits. This feature of the program implies in theory a labor informality bias. By applying matching techniques we provide some evidence in favor of this hypothesis. During the period of economic expansion the number of formal jobs available in the economy increased. According to some estimations, the share of PJH participants that found a formal job was significantly lower than the corresponding share for non-participants with similar observable characteristics. In some cases the difference is not only statistically significant, but economically large. The effect on informality vanishes in the period 2004-2005 when the gap between the PJH transfer (fixed in nominal terms) and wages in the formal sector greatly widened. The results of this paper suggest the relevance of paying attention to the design of certain features of poverty alleviation programs, as they may have unwanted consequences on some outcomes. A more careful design of social programs may avoid or alleviate some biases, and then make the programs more efficient and easier to sustain politically. 


\section{Appendix}

Figure A1. Histograms for the treated and untreated observations in the survey

\section{Panel 2003-2004}

Histogram propensity score for treated Full sample

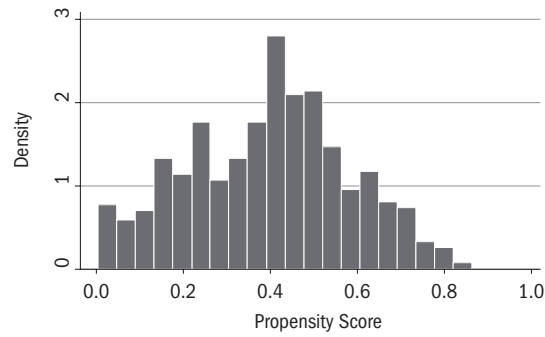

Histogram propensity score for treated Matched sample - Radio

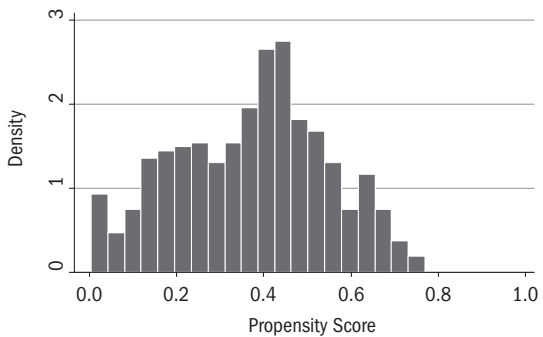

Histogram propensity score for treated Matched sample - Nearest neighbor

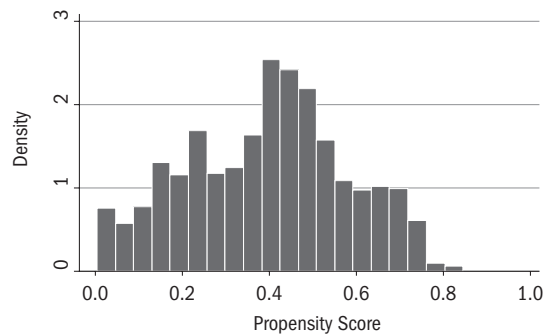

Histogram propensity score for untreated Full sample

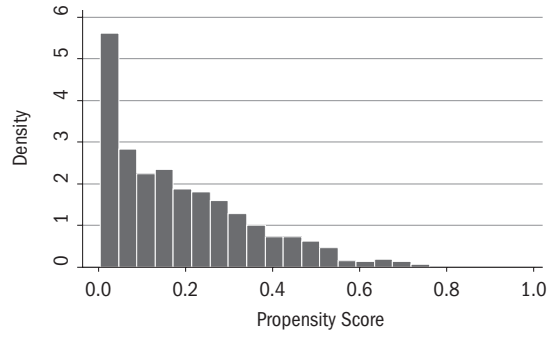

Histogram propensity score for untreated Matched sample - Radio

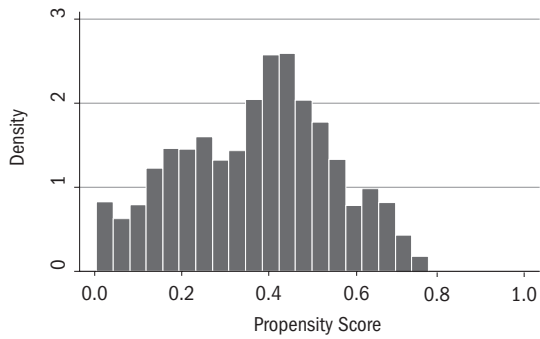

Histogram propensity score for untreated Matched sample - Nearest neighbor

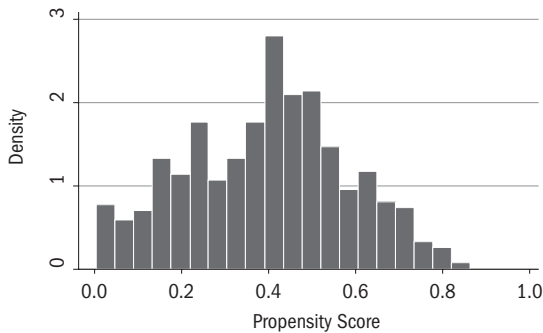

Source: own calculations based on the EPHC. 


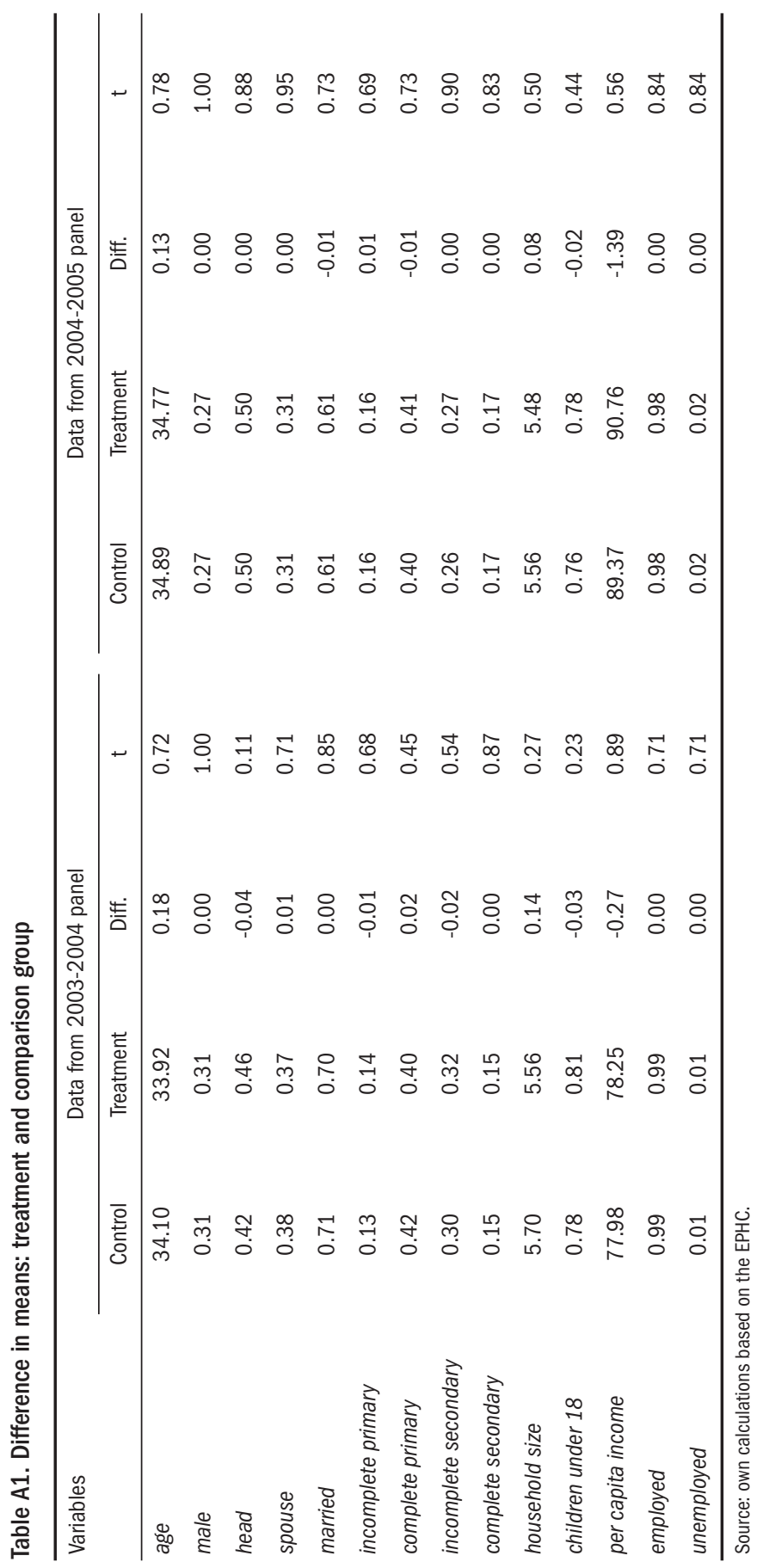




\section{References}

Abadie, Alberto, and Guido Imbens (2006a), Large sample properties of matching estimators for average treatment effects, Econometrica 74: 235-67.

Abadie, Alberto, and Guido Imbens (2006b), On the failure of the bootstrap for matching estimators, Technical Working Paper 325, Cambridge, MA, NBER.

Bogani, Esteban, Marco Grosso, Ernesto Philipp, Agustín Salvia, and Julio Zelarayán (2005), Aunque no alcance, se trata de sumar: El comportamiento de las mujeres, hombres y hogares participantes en el Plan Jefas y Jefes de Hogar Desocupados, Revista Argentina de Sociología 3: 187-205.

Galasso, Emanuela, and Martin Ravallion (2003), Social protection in a crisis: Argentina's Plan Jefes y Jefas, World Bank Economic Review 18: 367-399.

Gasparini, Leonardo (2006), Monitoring the socio-economic conditions in Argentina 1992-2006, working paper, CEDLAS and World Bank.

Gasparini, Leonardo, and Leopoldo Tornarolli (2007), Labor informality in Latin America and the Caribbean: patterns and trends from household survey microdata, Documento de trabajo 46, CEDLAS, UNLP.

Giovagnoli, Paula (2006), Poverty alleviation or political networking?, unpublished manuscript, London School of Economics.

Golbert, Laura (2007), Aprendizajes del Programa de Jefes y Jefas de Argentina, in I. Arriagada (coord.), Familias y políticas públicas en América Latina: una historia de desencuentros, Santiago, CEPAL, Naciones Unidas.

Lee, Myoung-jae (2005), Microeconometrics for policy, program, and treatment effects, New York, NY, Oxford University Press.

López Zadicoff, Pablo and Jorge Paz (2003), El Programa Jefes de Hogar. Elegibilidad, participación y trabajo, Documento de trabajo 242, Universidad del CEMA.

López Zadicoff, Pablo, and Jorge Paz (2004), Avus, el Genio y Silverix (El Programa Jefes de Hogar: Evaluación de objetivo), Jornadas de la Asociación Argentina de Economía Política, Buenos Aires.

Miller, Cynthia (2004), Programa Jefes de Hogar: participation and effects, unpublished manuscript, New York, Manpower Demonstration Research Corporation (MDCR).

Ministerio de Trabajo, Empleo y Seguridad Social (2004), Segunda evaluación del Programa Jefes de Hogar. Resultados de la encuesta a beneficiarios, Serie Estudios, Buenos Aires.

Monza, Alfredo, and Claudia Giacometti (2003), Los beneficiarios del Plan Jefes y Jefas de Hogar, Documento de Trabajo 1, Proyecto Cooperación OIT/Gobierno Argentino (MTSS): Enfrentando los retos al trabajo decente en la crisis Argentina, OIT/MTSS.

Moreno, Juan Martin (2008), Ud. volvería a lanzar el Plan Jefes? Una visión de los planes sociales y el mercado de trabajo en Argentina, unpublished manuscript, World Bank.

Perry, Guillermo, William Maloney, Omar Arias, Pablo Fajnzylber, Andrew Mason, and Jaime SaavedraChaduvi (2007), Informality. Exit and exclusion, Washington, D.C., Latin American and Caribbean Studies, World Bank.

Ravallion, Martin (2005), Evaluating anti-poverty programs, Working Paper 3625, World Bank Policy Research.

Ronconi, Lucas, Juan Sanguinetti, and Sandra Fachelli (2006), Poverty and employability effects of workfare programs in Argentina, PMMA Working paper 2006-14, Poverty and Economic Policy (PEP).

Toledo, Fernando (2007), Pobreza y capital social: dilucidando los procesos de una relación compleja. Un análisis para el caso del Gran Buenos Aires, master's thesis, Universidad Nacional de La Plata. 